\title{
Embryonal neural tumours and cell death
}

\author{
John Inge Johnsen · Per Kogner · Ami Albihn • \\ Marie Arsenian Henriksson
}

Published online: 4 March 2009

(C) The Author(s) 2009. This article is published with open access at Springerlink.com

\begin{abstract}
Medulloblastoma and neuroblastoma are malignant embryonal childhood tumours of the central and peripheral nervous systems, respectively, which often show poor clinical prognosis due to resistance to current chemotherapy. Both these tumours have deficient apoptotic machineries adopted from their respective progenitor cells. This review focuses on the specific background for tumour development, and highlights biological pathways that present potential targets for novel therapeutic approaches.
\end{abstract}

Keywords Medulloblastoma $\cdot$ Neuroblastoma ·

Apoptosis $\cdot$ Mitochondria $\cdot$ Novel therapy

$\begin{array}{ll}\text { Abbreviations } \\ \text { ALK } & \text { Anaplastic lymphoma kinase } \\ \text { BDNF } & \text { Brain-derived neurotrophic factor } \\ \text { BID } & \begin{array}{l}\text { Bcl-2 homology domain 3-interacting death } \\ \text { agonist }\end{array} \\ \text { BMP } & \text { Bone morphogenic protein } \\ \text { CNS } & \text { Central nervous system } \\ \text { CTL } & \text { Cytotoxic T-lymphocyte } \\ \text { DED } & \text { Death effector domain } \\ \text { DISC } & \text { Death-inducing signalling complex }\end{array}$

J. I. Johnsen · P. Kogner $(\bowtie)$

Childhood Cancer Research Unit, Department of Woman and Child Health, Karolinska Institutet, Astrid Lindgren Children's Hospital, Q6:05, Karolinska University Hospital, 17176 Stockholm, Sweden

e-mail: Per.Kogner@ki.se

A. Albihn · M. A. Henriksson

Department of Microbiology, Tumour and Cell Biology (MTC),

Karolinska Institutet, Box 280, 17177 Stockholm, Sweden

M. A. Henriksson

e-mail: marie.henriksson@ki.se
EGL External granular layer

FADD Fas-associated protein with death domain

FRET Fluorescence resonance energy transfer

GNP Granule neural precursor

HGF Hepatocyte growth factor

IAP Inhibitor of apoptosis protein

IGF Insulin-like growth factor

MAPK Mitogen-activated protein kinase

MCL-1 Myeloid cell leukaemia-1

NGF Nerve growth factor

NPM Nucleophosmin

NSAID Non-steriodal anti-inflammatory drug

NT Neurotrophin

PI3K Phosphatidylinositol 3-kinase

PNA Peptide nucleic acid

RA Retinoic acid

SCID Severe combined immunodeficiency

sPNET Supratentorial primitive neuroectodermal tumour

TGF Transforming growth factor

TNF Tumour necrosis factor

TRAIL TNF-related apoptosis-inducing ligand

VEGF Vascular endothelial growth factor

VIP Vasoactive intestinal peptide

\section{Clinical background; medulloblastoma and neuroblastoma}

Today the majority of children with cancer are curable with different combinations of chemotherapy, often used together with surgery and irradiation. The higher cure rate in childhood cancers compared to adult malignancies is related to paediatric tumours being more prone to apoptosis using current cytotoxic drugs, and children being able to 


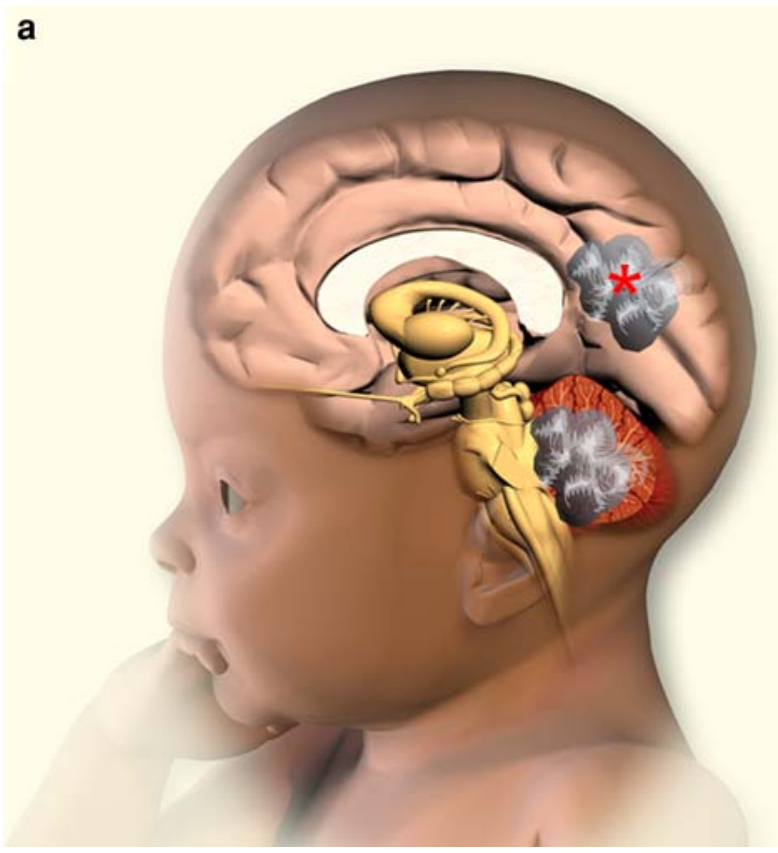

Fig. 1 Medulloblastoma and neuroblastoma localisation. (a) Medulloblastoma primary tumours arise in the infratentorial posterior fossa of the CNS whereas supratentorial primitive neuroectodermal tumours (sPNET) arise in the superior fossa (indicated by asterisk, *). (b) Neuroblastoma primary tumours derived from the neural crest arise

stand relative higher doses of chemotherapy than adults. However, despite recent progress, cancer is still the leading cause of childhood death due to disease in Western countries, and worldwide second to infectious diseases that have a very high prevalence in underdeveloped countries [1-4]. Today more than $75 \%$ of children can be cured from cancer, although the prognosis varies between different diagnoses and clinical subsets $[1,3]$.

Medulloblastoma and neuroblastoma are embryonal childhood tumours of the central and peripheral nervous systems, respectively, (Fig. 1) [5, 6]. Medulloblastoma most often arises in the cerebellum [when presenting outside the cerebellum called supratentorial primitive neuroectodermal tumour (sPNET), see Fig. 1a, in this review included in the medulloblastoma entity] and present mainly in young children with a clinical prognosis related to primary surgical resectablility and metastatic spread dependent on inherent biological features. Neuroblastoma arises in the sympathetic nervous system showing heterogeneous biological and clinical features with one subset of neuroblastoma prone to undergoing spontaneous apoptosis with little or no therapy, another subset differentiating over time, whereas the majority are tumours difficult to cure with current treatment modalities. Both medulloblastoma and neuroblastoma are unfavourable malignant tumours with relatively high proportion of children that die due to therapy resistant disease

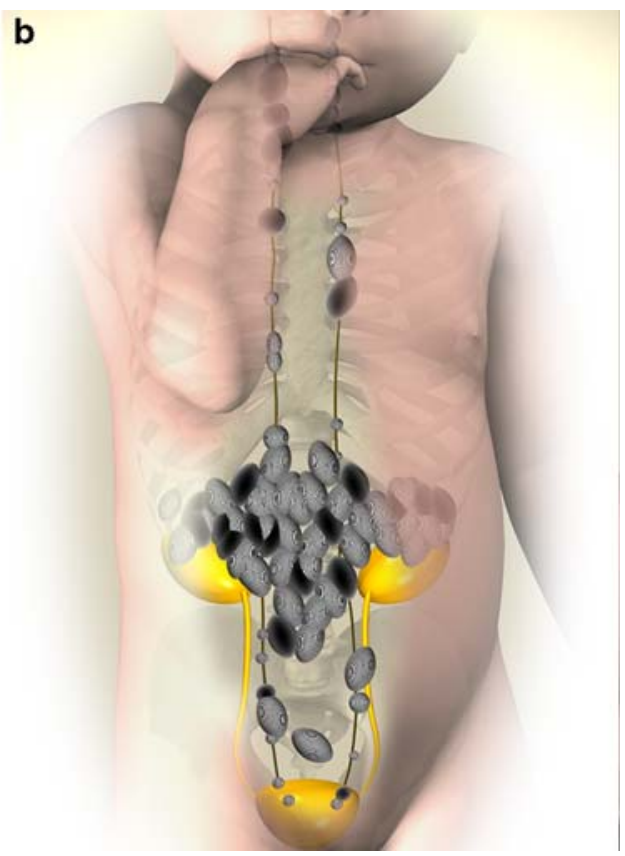

in the sympathetic nervous system including the adrenal medulla, sympathetic ganglia and paraganglia. Medulloblastomas metastasize primarily within the CNS whereas neuroblastomas mainly metastasize to lymph nodes, bone and bone marrow, and in infants also spread to liver and subcutaneous tissue

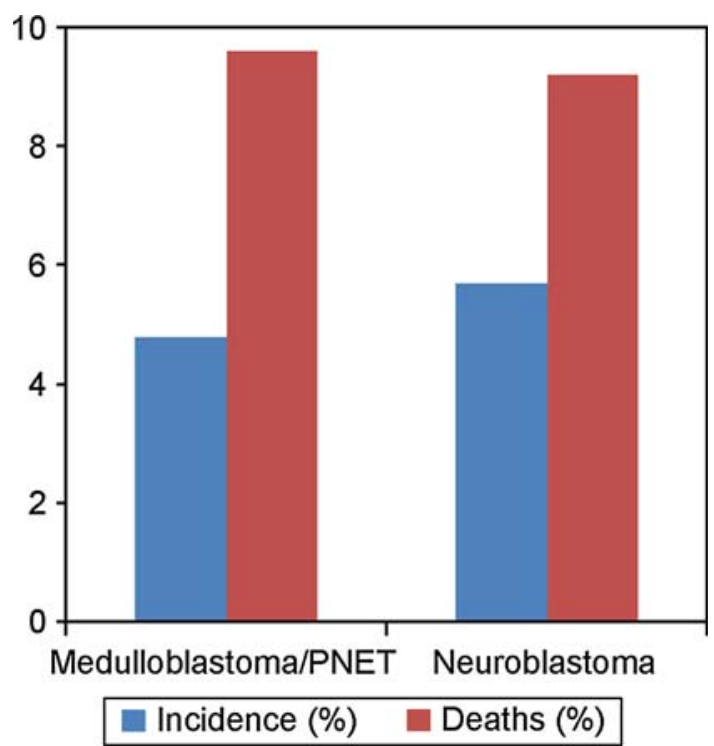

Fig. 2 Medulloblastoma and neuroblastoma incidence and mortality. Both these embryonal neural tumours show a worse outcome compared to all other childhood cancers, with relative more deaths (18.8\% of all) than diagnosed cases (10.5\% of all; population based data from Swedish Childhood Cancer Registry [3]). Relative incidence and mortality for medulloblastoma (4.8 and 9.6\%, respectively) and neuroblastoma (5.7 and 9.2\%, respectively) among all diagnosed cases and deaths of cancer in children $<15$ years, from their diagnosis 1984-2000 and followed until 2007 
(Fig. 2). Childhood malignancies, including medulloblastoma and neuroblastoma, not curable with current therapeutic modalities often show defects in the apoptotic machinery. Although further refined use of cytotoxic drugs may somewhat improve prognosis, development of novel therapies based on identification of specific targets seems the most promising way forward to better outcome for children with cancer [7, 8]. Both medulloblastoma and neuroblastoma belong to the most challenging oncologic diseases of childhood and serve as useful models for development of targeted therapy based on novel biological understanding. Amplification of the $M Y C N$ oncogene characterizes the subset of most aggressive neuroblastomas [6], whereas in medulloblastoma, activation of the c-MYC oncogene has been shown to be one of the most reliable prognostic factors [9, 10]. Even though $M Y C N$-amplification also occurs in medulloblastoma, its value as a prognostic factor has not been clearly established ([10] and reviewed in [11]). Despite intensive multimodal therapy, often resulting in good immediate response in many children, both high-risk neuroblastoma and metastatic medulloblastoma frequently acquire therapy resistance with fatal clinical outcome. Moreover, many of the survivors suffer great risks of severe consequences from the intensive treatment; in particular children with medulloblastoma that often experience long-term side effects mainly due to radiation therapy to the developing brain with high risks of severe morbidity even if cured from the tumour.

\section{Origin of embryonal tumours of the nervous system and mechanisms of apoptotic resistance}

The delicate balance between programmed cell death, proliferation, self-renewal, migration and differentiation is crucial for normal neural development. Defects in any of the mechanisms controlling these processes could promote transformation, making developing cells prone to tumourigenesis. During the last years, it has become increasingly clear that paediatric neoplasms of the nervous system are linked to disordered mechanisms of normal development, supporting a model of embryonic tumourigenesis [12]. Compared to adult tumours, embryonal tumours have a dramatically shortened latency period and generally harbour fewer genetic aberrations causing oncogene activation or loss of apoptotic regulators. The reason for these differences is that embryonic malignancies arise from progenitor cells which are already proliferating as a part of the normal developmental process [13]. The major molecular mechanisms controlling neural development consists of a handful of signalling transduction pathways of which Wnt, Hedgehog, Notch, BMP (bone morphogenic protein), TGF- $\beta$ (transforming growth factor- $\beta$ ) and receptor tyrosine kinases are the most important ones [14].
Medulloblastoma and neuroblastoma as developmental disorders

Recent discoveries have shown that normal development and tumourigenesis have several common characteristics. Both processes involve altered proliferation, differentiation, migration and apoptosis [15]. Medulloblastoma is believed to originate from cerebellar granule neural precursor (GNP) cells located in the external granular layer (EGL) of the cerebellum (Fig. 1a) [16, 17]. The EGL contains actively proliferating progenitor cells deriving from the rhombic lip during embryogenesis. While GNP cell proliferation requires Hedgehog signalling [18], their expansion and survival is also promoted by insulin-like growth factor (IGF) signalling [19]. Medulloblastoma cells retain many features resembling precursor cells of the embryonic brain [17] and more than half of these tumours contain abnormal activation of the Hedgehog or Wnt signalling pathways [20]. Neuroblastoma is an embryonal tumour of the peripheral nervous system that originates from neural crest cells and usually manifests in the adrenal gland or in a paraspinal location in the abdomen or chest (Fig. 1b) [6]. The neural crest is a transient embryonal structure that arises from ectoderm during closure of the neural tube. It consists of a population of multipotent progenitor cells that will differentiate into peripheral sensory neurons, cells in the enteric nervous system, Schwann cells, pigment cells, and parts of the craniofacial skeleton. A complex interplay between Hedgehog and Wnt signalling has been shown to be important for proper neural crest formation [21]. Both Hedgehog and Wnt signalling have been shown to induce expression of MYCN, a transcription factor that is widely expressed in the peripheral neural crest and has critical roles in the regulation of cell cycle progression, differentiation, and apoptosis (discussed below). High MYCN expression stimulates proliferation and migration of neuroblasts, while a reduced expression is associated with terminal differentiation [12]. Amplification of $M Y C N$ occurs in a large fraction of highrisk neuroblastoma and is associated with aggressive disease in children and poor clinical outcome [6]. Moreover, constitutive activation of phosphatidylinositol 3-kinase (PI3K)/ Akt as well as activation of Wnt signalling has recently been shown in primary neuroblastomas [22-24]. Activation of both these signalling pathways is associated with increased MYCN expression in neuroblastoma [22, 24, 25].

\section{Apoptosis in the developing nervous system}

During neural embryogenesis approximately $50-70 \%$ of the neural cells die through programmed cell death [26]. Cells that are committed to differentiate into neurons are more prone to undergo apoptosis compared to the neural 
progenitor cells which through different mechanisms are effectively protected against apoptosis [27]. Normal cells usually have a fine tuned equilibrium between the expression levels of pro-apoptotic and anti-apoptotic proteins. In neural progenitor cells as well as in medulloblastoma and neuroblastoma this equilibrium has been shifted towards less expression of pro-apoptotic proteins and higher expression of anti-apoptotic proteins.

A central component of the apoptotic process is a proteolytic system consisting of a family of cysteine-rich proteases called caspases. These enzymes participate in a cascade that is triggered by various extracellular (extrinsic) or intracellular (intrinsic) stress signals and culminate in
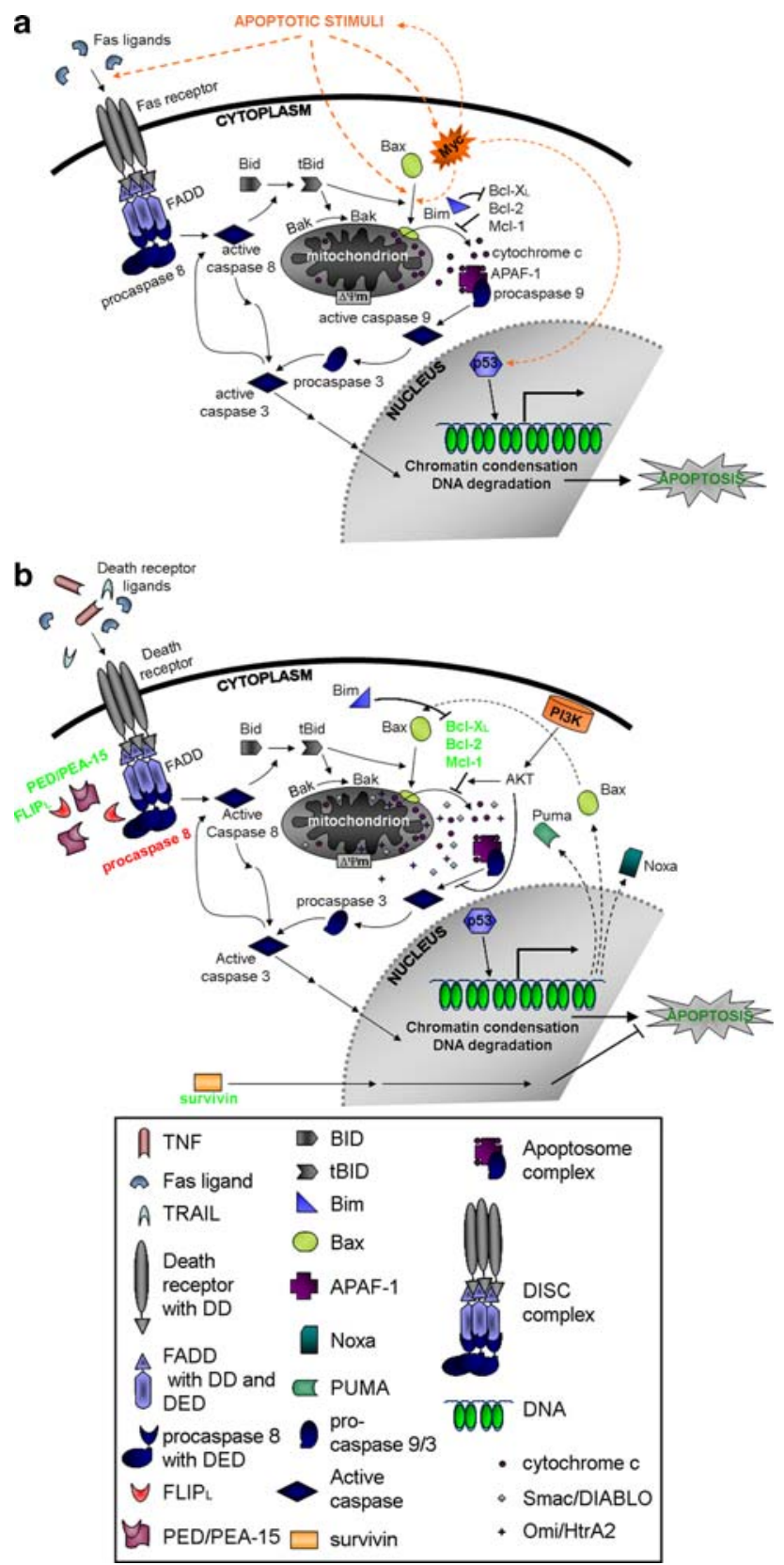

cleavage of a set of proteins resulting in disassembly of the cell into apoptotic bodies (Fig. 3a) [28]. Caspases have been assigned into three major classes: initiator caspases such as caspase-2, -4, -8, -9, -10, and -12; effector caspases such as caspase- $3,-6$ and -7 ; and inflammatory caspases such as caspase-1, -5 and -11 depending on their roles in mediating cell death and inflammatory responses [29]. Antagonising these caspases are a family of proteins called inhibitor of apoptosis proteins (IAPs) that block apoptosis by direct binding to caspases [30]. Currently there are nine known IAPs: X-linked IAP, cIAP1, cIAP2, melanoma IAP, neural apoptosis inhibitor protein, IAP-like protein 2, livin, apollon and survivin [31]. The functions of IAPs are in turn inhibited by endogenous antagonists like Smac/DIABLO, $\mathrm{Omi} / \mathrm{HtrA} 2$ and XAF1. Smac/DIABLO and Omi/HtrA2 are released from the mitochondria along with cytochrome $c$ whereas XAF1 binds and sequesters XIAP in the nucleus thus preventing XIAP to inhibit cytosolic caspases (reviewed in [32]). Also located to the mitochondria is the Bcl-2 family of proteins that plays a central role in controlling the intrinsic mitochondrial-dependent apoptotic signalling. To date more than 20 members of this family have been identified in humans, including suppressors (Bcl-2, Bcl- $\mathrm{X}_{\mathrm{L}}$, Bcl-G, Bcl-W, Bfl1/A1, Mcl-1) and promoters (Bcl-X $\mathrm{X}_{\mathrm{S}}$, Bax, Bak, Bid, Bad, Bok, Bik, Bim, Bcl-B, Noxa, Nix, Nip3, Puma, Hrk, Mtd) of apoptosis [33, 34]. This family modulates apoptosis by modulating the permeability of inner and/or outer mitochondrial membranes leading to the deterrence or release of cytochrome $c$.

Fig. 3 Apoptosis pathways and their regulation in medulloblastoma and neuroblastoma. Schematic overview of the two major apoptosis pathways: the extrinsic death receptor pathway and the intrinsic mitochondrial pathway. A selection of molecules involved and their potential interactions in response to apoptotic stimuli is shown in (a). Stimuli such as death receptor ligands (Fas ligand, TNF, or TRAIL) enable assembly of the death-inducing signalling complex (DISC), leading to caspase- 8 cleavage and activation. Active caspase- 8 can either bridge over to the mitochondrial pathway by cleavage and activation of Bid, or activate a caspase cascade via the effector caspase-3 which will ultimately result in chromatin condensation and DNA degradation. In the intrinsic pathway, tBid will activate pro-apoptotic Bak or Bax to enable the release of molecules from the intermembrane space of mitochondria. Of the pro-apoptotic molecules (Smac/DIABLO, Omi/HtrA2, and cytochrome $c$ ), cytochrome $c$ binds to APAF-1 and forms the apoptosome complex together with procaspase-9, leading to caspase-9 activation and downstream events. Among the many ways for activated Myc to stimulate apoptosis are enabling activation of either Bax (at the mitochondria) or p53 (transcription of pro-apoptotic genes), or enhancing the Fas-mediated apoptosis signalling [122]. Anti-apoptotic Bcl-2 family members (Bcl-2, Bcl- $\mathrm{L}_{\mathrm{L}}$, and Mcl-1) prevent mitochondrial pore formation and subsequent cytochrome $c$ release, and are in turn inhibited by BH3-only molecules such as Bim. (b) Simplified schematic of key molecules involved in regulating apoptosis in medulloblastoma and neuroblastoma. Molecules that are labelled in green are proteins reported to be overexpressed, and the ones labelled in red are molecules reported to be inhibited in medulloblastoma and neuroblastoma 


\section{Aberration of the extrinsic apoptotic pathway}

Neural progenitor cells are effectively protected against extracellular death signals acting on the extrinsic apoptotic pathway [33]. This is partly demonstrated by the dismal expression of caspase- 8 in these progenitor cells, whereas the DED (death effector domain)-containing anti-apoptotic protein PED/PEA-15 is overexpressed (Fig. 3b) [35]. Absence of caspase-8 expression is also commonly observed in primary medulloblastoma and neuroblastoma [36-39]. In both these tumours, epigenetic silencing through gene hypermethylation has been demonstrated as the mechanism resulting in reduced caspase- 8 expression [38-41]. In medulloblastoma loss of caspase-8 expression was significantly correlated with poor prognosis [36], while in neuroblastoma some reports show a correlation between caspase- 8 hypermethylation and poor prognosis whereas others do not [37-40]. Loss of caspase-8 protein expression has also been shown to be correlated to $M Y C N$ amplification in some studies, suggesting a tumour suppressor function in neuroblastoma [38, 40]. However, a recent study analysing a large cohort of neuroblastoma patients detected loss of caspase- 8 expression in the majority of tumours but no correlation was found either to poor prognosis, or to $M Y C N$ amplification [37]. In addition, FLIP $_{\mathrm{L}}$, a structural homologue of caspase-8 lacking caspase activity, has been shown to be overexpressed in neuroblastoma (Fig. 3b) [42]. When overexpressed, FLIP $_{\mathrm{L}}$ acts as an inhibitor of apoptosis by incorporating into the death-inducing signalling-complex (DISC) where it inhibits the activation of caspase-8 [43]. Taken together, these studies suggest that caspase- 8 has an important function in the development and progression of embryonic tumours of the nervous system and that the loss of caspase- 8 expression or activation in these tumours reflect the developmental status of the neural cells at the time of malignant transformation [44].

\section{Deregulation of the intrinsic apoptotic pathway}

Although several pathways of apoptosis have been linked to neural development, knockout of apoptotic genes in mice suggest that the intrinsic apoptotic pathway also is fundamental in neural progenitor cells [27]. The antiapoptotic mitochondria-associated proteins $\mathrm{Bcl}-2, \mathrm{Bcl}-\mathrm{X}_{\mathrm{L}}$, Mcl-1 and survivin are all highly expressed in the developing neural tissue indicating that these proteins are important for the survival of progenitor cells [31, 45, 46]. Among these, myeloid cell leukaemia-1 (Mcl-1) has recently been shown to be absolutely required for neural precursor cell survival [46]. Mcl-1 contains a PEST domain leading to a rapid protein turnover and short half-life [47]. This rapid induction and degradation suggests that Mcl-1 plays an important role in apoptotic control in multiple cell types in response to rapidly changing environmental cues [48]. The exact molecular mechanism by which Mcl-1 promotes cell survival is not fully understood but is thought to involve inhibition of cytochrome $c$ release from mitochondria, possibly via heterodimerisation with and neutralisation of pro-apoptotic Bcl-2 family proteins [49].

Several studies have suggested that Bcl-2 is an important regulator of apoptosis in cerebellar GNP cells from which medulloblastomas are thought to arise [50, 51]. The Hedgehog pathway effector Gli-1 has been shown to induce $\mathrm{Bcl}-2$ expression whereas pharmacological suppression of Hedgehog activity resulted in decreased Bcl-2 expression and increased apoptosis [52]. It has also been shown that postnatal overexpression of Bcl-2 in cooperation with Hedgehog induces high frequency of medulloblastomas in mice. However, expression of endogenous Bcl-2 was not up-regulated in Hedgehoginduced tumours. Instead, elevated levels of phosphorylated Akt were found, suggesting that activated PI3K signalling is one intrinsic mechanism for suppressing apoptosis in Hedgehog-dependent medulloblastomas [53].

In neuroblastoma, pro-apoptotic mediators of the intrinsic apoptotic pathway were found to be expressed to a lower extent in tumours with unfavourable biology suggesting that mitochondrial-dependent apoptosis is suppressed in advanced stage disease and linked to unfavourable clinical outcome [54]. In contrast, overexpression of Bcl-2 has been shown to be correlated to poor prognosis and MYCN amplification in neuroblastoma [42, 55]. Moreover, Bcl-2 is a powerful antagonist of MYCN-augmented apoptosis in neuroblastoma [56].

Myeloid cell leukaemia-1 maps to a region of chromosome $1 \mathrm{q}$ that is frequently gained in high-risk neuroblastomas and the protein is highly expressed in malignant cells $[44,47]$. Gain of chromosome $1 \mathrm{q}$ is a negative prognostic marker for survival also in medulloblastoma [57], but so far no correlation to the expression of Mcl-1 has been reported. Survivin is encoded by a single-copy gene located on human chromosome $17 \mathrm{q} 25$, a region that is frequently gained in unfavourable medulloblastoma and highrisk neuroblastoma [58-60]. Moreover, elevated expression of survivin is highly correlated to poor survival in both medulloblastoma and neuroblastoma (Fig. 3b) [60-62]. In normal cells the synthesis and degradation of survivin is modulated in a cell cycle-specific manner and survivin functions primarily as a mitotic regulator [63, 64]. However, in cancer cells survivin expression has been shown to be deregulated by several mechanisms, including $\mathrm{p} 53$ mutation, amplification at the gene locus [60], demethylation of exons [65], increased promoter activity [64], or increased upstream signalling of PI3K/Akt or MAPK pathways [66]. Furthermore, the upregulation of survivin expression in cancer cells 
seems to be independent of the cell cycle, suggesting an enhancement of its anti-apoptotic role [31].

\section{p53 and related proteins}

The TP53 gene encoding the $\mathrm{p} 53$ protein is probably the most commonly mutated gene in human cancers but it is infrequently mutated in primary childhood tumours including medulloblastoma and neuroblastoma [6, 67, 68]. However, inactivation of p53 contributes significantly to medulloblastoma and neuroblastoma development in specific animal models [69-71]. Furthermore, individuals with the Li-Fraumeni syndrome carrying germ-line mutations of p53 may develop medulloblastoma, and isochromosome 17q implicating loss of $17 \mathrm{p}$ including TP53 is the most common genetic aberration in PNET differentiating between infratentorial medulloblastoma and sPNET [72, 73]. Although uncommon, primary somatic mutations of TP53 have been linked to the anaplastic medulloblastoma subset [74]. Wild type p53 is not infrequently inactivated in medulloblastoma due to aberrations in the p53-ARF pathway including HDM2 and WIP1/PPM1D [75, 76]. In neuroblastoma cell lines established at relapse p53 mutations are more frequent, indicating a role in the development of a therapy resistant phenotype [77, 78]. In addition, p53 dysfunction in neuroblastoma has been linked to HDM2 amplification, WIP1/ PPM1D activation, cytoplasmic sequestration, and TWISTImediated suppression [79-81]. Homozygous deletions of CDKN2A (INK4A/p16) a regulator of p53 stabilization, has been identified in neuroblastoma cell lines and recently in a subset of unfavourable primary neuroblastomas [82, 83]. Likewise, alterations of the p53 homologue, p73 have also been shown to contribute to inhibition of apoptosis in neuroblastoma. Expression of the oncogenic p73 isoform $\Delta \mathrm{Np} 73$ has been associated with decreased survival in both neuroblastoma and medulloblastoma $[84,85]$.

\section{ALK and neuroblastoma}

Anaplastic lymphoma kinase (ALK) is an orphan tyrosine kinase first identified as being activated by the $t(2 ; 5)(\mathrm{p} 23 ; \mathrm{q} 25)$ ALK-nucleophosphmin (NPM) translocation in anaplastic non-Hodgkin lymphomas and later shown to be oncogenic also in other neoplasias and dominantly expressed during neural development [86-88]. Besides expression in the normal developing neural system the ALK protein is expressed in neuroblastoma tumours and cell lines and some of these respond to ALK-specific small molecule inhibitors [89, 90]. Recently, specific germline mutations targeting the ALK tyrosine kinase domain were described in families with hereditary neuroblastoma and subsequently somatic mutations and gene amplifications were detected in sporadic primary tumours predominantly of metastatic stage or locally advanced tumours [91-95]. Specific knockdown of ALK expression in sensitive neuroblastoma cell lines in vitro as well as treatment using small molecule inhibitors (TAE684 and PF2341066) could inhibit cell proliferation and expression of downstream targets, and induce apoptosis. These preliminary results indicate that children with neuroblastoma could favour from future clinical application of ALK-specific targeted therapy that is under development [96].

\section{Signal transduction and apoptosis in medulloblastoma and neuroblastoma}

In addition to inactivation of apoptotic pathways, constitutive survival signalling can inhibit apoptosis. Neural progenitor cells, like other cell types, need trophic factors for their survival [97]. Neurotrophic factors like BDNF (brainderived neurotrophic factor), NT-3 (neurotrophin-3), NT-4/5 (neurotrophin-4/5) and NGF (nerve growth factor) act through binding to their cognate tropomysin receptor kinases (TrkA,TrkB and TrkC) and p75 neurotrophin receptor $\left(\mathrm{p} 75^{\mathrm{NTR}}\right)[98,99]$. Brain-derived neurotrophic factor and TrkB are required for the survival and protection of normal neurons [98] and aggressive high-risk neuroblastomas contain high levels of BDNF and elevated expression of the TrkB receptor $[100,101]$. On the other hand, favourable lowrisk neuroblastoma prone to differentiation or regeression through apoptosis, expresses high levels of both the highaffinity NGF receptor TrkA, and the low affinity receptor $\mathrm{p} 75$ [102-104]. Similarly, different expression levels of Trk receptors also occurs in medulloblastoma with high expression of the NT-3 receptor TrkC being indicative of a favourable outcome [10, 105]. High TrkC expression is also found in favourable neuroblastoma although TrkA is a more reliable prognostic indicator [104, 106, 107]. Binding of neurotrophins to their receptors leads to the activation of downstream signalling pathways including PI3K/Akt, Ras/ Raf/MAPK and phospholipase C- $\chi$ [108]. During the last years it has become increasingly clear that activation of $\mathrm{PI} 3 \mathrm{~K} /$ Akt signalling is an essential anti-apoptotic event and $\mathrm{PI} 3 \mathrm{~K} /$ Akt directly targets a number of pro- and anti-apoptotic proteins (reviewed in [109]). A majority of both medulloblastoma and neuroblastoma primary tumours constitutively express activated Akt [22, 23, 110], and inhibition of PI3K/Akt signalling induces apoptosis of neuroblastoma cells [22, 25]. Moreover, activated Akt significantly augments Hedgehog-induced medulloblastoma in mice and activation of PI3K/Akt signalling is important for the proliferation of cancer stem cells residing in the perivascular niche following radiation of medulloblastoma [111]. Both 
Hedgehog and IGF signalling have been found activated in medulloblastoma, but their respective roles in the disease have not yet been established [112]. In mice, Hedgehog appears to cooperate with MYCN in inducing medulloblastoma. Recently, it has been suggested that expression of Mxd3 (or Mad3), a member of the Mxd family of Myc antagonising transcription factors, is associated with MYCN expression [113]. In mouse models, Mxd3 has been found upregulated in medulloblastoma but, even though the protein is expressed during S-phase in proliferating cells, it does not appear to antagonise MYCN [113, 114]. The other three members of the Mxd family (Mxd1, 2, and 4) are expressed in differentiated cells [115].

Another potential contributor to medulloblastoma, hepatocyte growth factor (HGF), has been suggested to be functionally linked to c-Myc by inducing its expression on both mRNA and protein level [116]. This involved PI3K signalling as well as the Wnt pathway. Interestingly, the HGF-mediated induction of c-Myc also promoted proapoptotic effects by downregulation of Bcl-X $\mathrm{L}_{\mathrm{L}}$ [116]. Since c-Myc appears to play a causal role in inducing anaplasia, observed mainly in recurrent medulloblastoma, c-Myc deregulation is proposed to be involved in disease progression rather than its induction [117].

\section{The MYC protein network and apoptosis}

Amplification of the MYCN oncogene observed in 40-50\% of high-risk neuroblastoma cases is one of the key predictors of poor outcome and is associated with advancedstage disease, rapid tumour progression and a low survival rate despite intensified treatment [6]. Alternative treatment options for children with $M Y C N$-amplified neuroblastoma are therefore urgently needed.

MYCN belongs to the MYC network of transcriptional regulators that plays a key role in regulation of cell growth, apoptosis and differentiation. While the $c-M Y C$ gene is expressed in a wide variety of tissues at all stages of the life-cycle, MYCN expression is restricted to neuronal tissue, mainly during early stages of embryonic development. A link between the transformed phenotype and MYCN has been established by a range of in vitro and in vivo studies, including the transgenic mouse model of neuroblastoma in which $M Y C N$ overexpression targeted to neuronal tissue by the use of a tyrosine hydroxylase promoter leads to development of neuroblastoma in transgenic animals [71]. Downregulation of MYCN expression either by antisense treatment targeted against $M Y C N$ mRNA or by retinoids has been shown to decrease proliferation and/or induce neuronal differentiation of neuroblastoma cells [6].

c-MYC, the best studied member of the network, is expressed during all stages of the cell cycle in dividing cells and is normally downregulated during differentiation. MYC sensitizes cells to apoptosis induced by different cellular insults, such as ligation of the Fas death receptor and serum deprivation [118]. The ability of c-MYC to potentiate the apoptotic effects of many mechanistically distinct inducers indicates that c-MYC acts in a general control and/or execution apoptosis pathway.

The biological effects of MYCN are very similar to those of c-MYC. Inactivation of the strict regulation of MYC protein expression results in uncontrolled cell proliferation [119]. The enlarged pool of proliferating cells may enhance the risk of secondary mutations contributing to tumour development. Mutations in the apoptotic program results in an imbalance between proliferation and cell death with predominance for the former, thereby facilitating MYC-driven tumourigenesis. $M Y C$ is activated in a number of different tumours such as small cell lung cancer, breast carcinoma, medulloblastoma, glioblastoma, myeloid leukaemia, plasma cell leukaemia, Burkitt's lymphoma and neuroblastoma [120]. The frequent amplification of the MYCN gene, an established causal link between the malignant phenotype and the resistance to treatment, together with the restriction of expression in normal tissues to early stages of development makes MYCN an attractive therapeutic target to explore.

Deregulated MYC expression has been reported to enhance tumour cell death in response to anti-cancer agents [121-123]. One pioneering study in this field showed that MYCN synergizes with the cytotoxic drug doxorubicin to promote apoptosis through upregulation of the Fas receptor, enhancing sensitivity to Fas ligand signalling, and induction of p53 and Bax protein expression [122]. In this way, MYCN targets both the extrinsic and the intrinsic pathway of apoptosis induction in response to drug treatment (Fig. 3a). This data suggests that the MYCN amplification observed in high-risk neuroblastoma is not solely responsible for the aggressiveness of the tumour but that additional cellular aberrations are required in order to promote the dysfunction in apoptosis signalling. Although recent data suggest that activation of oncogenic c-MYC enhances drug-induced apoptosis through mitochondria by Bax activation [121, 124], the precise mechanism linking MYC and mitochondrial function in neuroblastoma cells is still unclear. Overexpression of Bcl-2 and $\mathrm{Bcl}-\mathrm{X}_{\mathrm{L}}$, in neuroblastoma cells may contribute to the drug resistance, characteristic of high-risk neuroblastomas [125]. Other studies confirm that the pro-apoptotic effect of cytotoxic drugs is enhanced in neuroblastoma cells with MYCN overexpression compared to the effect in cells with wild type MYCN levels [121, 123]. However, screening of a panel of 80 well defined drugs together with selected small molecules with different mechanisms of action revealed that only a limited subset show a MYC-specific apoptosis 
response (A. Albihn, M. Vita, H. Zirath, and M. Henriksson, unpublished data).

\section{Targeting apoptotic pathways in medulloblastoma and neuroblastoma}

The therapeutic modalities currently used in the clinic to kill tumour cells, including chemotherapy and $\gamma$-irradiation, exert their effects by triggering apoptosis. Although both medulloblastoma and neuroblastoma initially often respond well to current therapy, relapsed tumours have commonly acquired resistance to cytotoxic agents. Hence, the development of novel therapeutic approaches to overcome this apoptotic resistance is of great importance in the treatment of patients with these diseases. Current strategies to overcome the evasion of cancer cells from apoptosis include agents acting directly on apoptotic molecules aberrantly expressed in cancer cells and indirectly through the inhibition of signal transduction pathways that are crucial for cancer cell proliferation.

\section{Activation of death receptor-mediated apoptosis}

Death receptors are members of the tumour necrosis factor (TNF) receptor family of proteins. These proteins share similar extracellular cysteine rich domains and contain a cytoplasmic death domain which is essential for the transmission of death signals from the cell surface to the intracellular apoptotic pathways [126]. Although several death receptors of the TNF family have been characterized, the most promising in cancer therapy is TNF-related apoptosis-inducing ligand (TRAIL) receptors (TRAIL-R1 and TRAIL-R2; [127]). Compared to other TNF proteins, TRAIL has preferential selectivity for triggering apoptosis in tumour cells and is less active in normal cells. TRAIL also acts as an important immune effector molecule in the surveillance and in the elimination of developing tumours [127]. TRAIL, has been shown to bind to at least five receptors. Two of them (TRAIL-R1 and TRAIL-R2) are capable of transducing an apoptotic signal, whereas the other three (TRAIL-R3, TRAIL-R4, and the soluble receptor OPG) serve as decoy receptors to block TRAILmediated apoptosis. Once activated, both TRAIL-R1 and TRAIL-R2 bind to the cytoplasmic adaptor molecule Fasassociated protein with death domain (FADD) which then recruits the initiator caspases, caspase- 8 or caspase- 10 [126]. Proteolytic activation of the initiator caspases is followed by activation of downstream effector caspases, such as caspase-3, which cleaves numerous cellular proteins ultimately leading to apoptotic cell death [126]. One therapeutic advantage of activating apoptosis through death receptors is that the extrinsic pathway bridges over to the intrinsic pathway since caspase- 8 activation has been shown to activate the $\mathrm{Bcl}-2$ homology domain 3-interacting death agonist (Bid). Truncated Bid (tBid) activates the intrinsic apoptotic pathway by interacting with Bax, Bak, or by blocking pro-survival Bcl-2 family proteins [127].

Resistance to TRAIL-mediated apoptosis due to loss of caspase-8 expression has been demonstrated in both medulloblastoma and neuroblastoma (see above). Although DNA methyltransferase inhibitors and IFN $-\gamma$ have been shown to restore caspase- 8 and sensitize neuroblastoma cells to TRAIL-mediated apoptosis, a number of neuroblastoma cell lines are still resistant to death receptor-mediated apoptosis [128-130]. Interestingly, several reports have demonstrated that cytostatic drugs augment TRAIL-induced apoptosis, and more importantly sensitise cancer cells that are resistant to TRAIL (reviewed in [127]). The cancer cell sensitivity to TRAIL has also recently been shown to be enhanced when the Bcl-2 family protein Mcl-1 is downregulated by the Raf/vascular endothelial growth factor (VEGF) kinase inhibitor sorafenib [131]. Hence, the combination of TRAIL with cytostatic drugs is an interesting approach for cancer treatment.

Indeed, several clinical trials using soluble recombinant TRAIL (rTRAIL) and monoclonal antibodies (mAbs) targeting TRAIL-R1, such as mapatumumab, and TRAIL-R2, such as lexatumumab, AGM 655 and apomab, have shown promising results in combination therapies. However, it is important to recognize that the utility of rTRAIL and agonistic anti-TRAIL mAb therapies was limited to TRAIL-sensitive tumours and that some of these agents may cause hepatocyte-and bile ducts-toxicities [127].

\section{Targeting Bcl-2 homology proteins and the intrinsic apoptotic pathway}

The balance between pro-apoptotic and anti-apoptotic members of the Bcl-2 protein family is crucial in controlling the activation of the intrinsic apoptotic pathway. Members of the Bcl-2 protein family control the release of apoptogenic factors (cytochrome $c$, Omi/HtrA2 and Smac/ DIABLO) from the inter-membrane space of mitochondria. The survival promoting members of the $\mathrm{Bcl}-2$ family of proteins (Bcl-2, Bcl- $\mathrm{L}_{\mathrm{L}}, \mathrm{Bcl}-\mathrm{W}, \mathrm{Bcl}-\mathrm{G}, \mathrm{Bfl} 1 / \mathrm{A} 1$ and Mcl1) all contain four Bcl-2 homology domains (BH1-4), with the exception of Mcl-1, which lacks the BH4 domain. All these proteins are critical for cell survival and have been found overexpressed in a number of different tumour samples. The pro-apoptotic Bcl-2 homology proteins can be divided into two classes; the $\mathrm{Bax}$ (Bcl-2-associated protein $\mathrm{X}$ )-like proteins (Bax, Bak, and Bok) that contain three $\mathrm{BH}$ domains and the $\mathrm{BH} 3$-only proteins (Bim, Bid, 
Bmf, Bad, Bik, Puma, Noxa, and Hrk). The BH3 domain forms an amphipathic alpha helix that enables binding to other BH domains and inhibition of the pro-survival function of Bcl-2 proteins (reviewed in [132]).

Several lines of evidence suggest that suppression of the intrinsic apoptotic pathway is important in medulloblastoma and neuroblastoma (see above), making $\mathrm{Bcl}-2$ homology proteins a possible target for designing novel therapy. A number of genetic and pharmacological approaches have recently been developed to target $\mathrm{Bcl}-2$ homology proteins. Targeting the expression levels of Bcl2 using G3139 (Oblimersen), an anti-Bcl-2 antisense oligonucleotide, has shown promising results and phase III clinical trials have recently been completed in advanced melanoma, myeloma, and chronic lymphocytic leukaemia [133]. In addition, peptide-based drugs containing prodeath $\mathrm{BH} 3$ minimal death domains have been shown to attenuate Bcl-2 function. In neuroblastoma, BH3 peptides activated apoptosis and demonstrated single agent efficacy in vivo [134]. Although peptides represent an intriguing pharmaceutical class, they have potential drawbacks including limited serum stability and cellular absorption. Therefore, a new class of small inhibitors of Bcl-2 homology proteins have currently attracted much attention. These agents are either derived from natural products like epigallocatechin-3-gallate from tea extracts or gossypol isolated from cottonseeds and roots or from in vitro screening of chemical compounds that interact with $\mathrm{BH} 3$ domains (reviewed in $[135,136]$ ). Although some of these agents have shown promising effect and safety in clinical phase I and phase II trials, more studies will be needed to estimate the true value of these inhibitors.

\section{Targeting inhibitor of apoptosis proteins (IAPs)}

The main function of IAPs is to inhibit the activation of effector caspases. Since IAPs inhibit apoptosis downstream of several signalling pathways they are attractive as therapeutic targets.

The IAP that has attracted most attention as a potential target for cancer therapy is survivin, since it is selectively expressed in most human cancers, including medulloblastoma and neuroblastoma. Several experimental therapeutic strategies have been developed to target survivin. These include targeting RNA expression, small molecule inhibitors of survivin function, or vaccination strategies to generate an antigen-specific immune response against survivin [31]. This latter strategy might prove efficient in neuroblastoma since children with high-risk neuroblastoma harbour robust cellular immune responses to survivin at the time of diagnosis [137]. Two transcriptional repressors of survivin, YM155 and EM-1421, have recently entered clinical trials but so far only modest anti-tumour activity has been obtained [31]. One perhaps even more interesting finding is that several other anti-cancer agents like ARC (4amino-6-hydrazino-7-beta-D-ribofuranosyl-7H-pyrrol-

o[2,3-d]-pyrimidine-5-carboxamide), histone deacetylase inhibitors, and non-steroidal anti-inflammatory drugs (NSAIDs), shown to be effective apoptosis inducers in preclinical medulloblastoma and neuroblastoma therapy, also indirectly inhibit the expression of survivin [138-143].

\section{Targeting MYC and the MYC pathway}

As mentioned above, $M Y C N$ is frequently amplified in severe cases of neuroblastoma and is a marker for bad prognosis. Therefore, selective targeting of $\mathrm{MYCN}$ in neuroblastoma cells provides a promising treatment strategy. In effect, the antisense technique has been explored for inhibition of MYCN [144, 145]. The use of antisense oligonucleotides resulted in suppression of cell proliferation, induction of differentiation, and apoptosis [145]. Similar effects were observed in response to the more sophisticated peptide nucleic acids (PNA), designed to selectively inhibit MYCN in neuroblastoma cells [145]. Pession et al. [144] also showed that neuroblastoma cells without MYCN amplification were not sensitive to the PNA treatment. Promising effects of the antisense approach have also been demonstrated in vivo, treating transgenic mice with $M Y C N$-induced neuroblastoma with oligonucleotides that were either antisense or scrambled [146]. No effect was observed with the scrambled oligonucleotides whereas the antisense downregulated MYCN expression by half and significantly reduced tumour mass.

Another potential approach for targeting MYCN is vaccine therapy [147]. In this study, cytotoxic T-lymphocytes (CTLs) raised to a peptide derived from a patient with $M Y C N$-amplified neuroblastoma were found to selectively lyse HLA-matched $M Y C N$-amplified neuroblastoma cells. In contrast, non- $M Y C N$-amplified neuroblastoma cells, or HLA-mismatched cells were not lysed by the CTLs.

The strategy to target MYCN as a tumour treatment approach is beneficial due to its expression pattern, being restricted to cells of neuronal origin during embryogenesis. In the case of c-Myc on the other hand, its nearly ubiquitous expression in proliferating cells complicates a similar approach since targeting such a vitally important protein might have detrimental effects on continuously regenerating tissues. However, recently Soucek and colleagues elegantly showed that transgenic mice could tolerate the effects of extended Myc inhibition while their K-Rasinduced lung tumours regressed almost completely. Their approach was to employ conditional expression of the dominant interfering Myc bHLHZip dimerization domain 
mutant Omomyc [148]. Even though proliferating tissues such as intestinal crypts and the skin were heavily affected, they were reverted within 1 week after restoring normal Myc function by shutting down Omomyc and animals appeared unaffected. While this study requires translation into human subjects, it provides reassurance that pharmacological inhibition of c-Myc is possible and may even be the preferred means of treating Myc-driven tumours.

One way of targeting Myc would be through the use of small molecules. These could be identified by screening or by rational design to target the Myc pathway at different levels such as blocking its transcription or translation, promoting Myc protein degradation, blocking transcription of Myc target genes by either disrupting Myc/Max dimerization or preventing Myc/Max DNA binding, or interfering with Myc interaction with other factors (i.e. the TRRAP-histone acetylase complex or E3 ligases). They could also affect indirectly by inhibiting the function of key Myc target genes (reviewed in [120]). There are several advantages in identifying small molecules that affect the desired cellular function or target the appropriate molecule. Their small size makes them easy to handle, relatively cheap to synthesize, easy to modify in order to improve their solubility and absorption, and reduce potential toxicity once a positive substance has been identified. Hence, there have been several studies screening for molecules targeting Myc at different levels, the majority of which focus on the c-Myc protein, but also for MYCN targeting molecules. Berg et al. [149] used the fluorescence resonance energy transfer (FRET) technique to screen 7,000 small molecules and identified four compounds that inhibited the formation of Myc/Max complexes. Interestingly, two of the inhibitors were effective in inhibiting soft agar growth of Myc transformed chicken embryo fibroblasts but did not inhibit Src-transformed cells and thus showed specificity for Myc. Using a yeast two-hybrid approach, Yin et al. screened a library of 10,000 compounds and identified several substances that inhibited Myc transactivation and resulted in decreased growth of Myc transformed cells. Seven of these compounds elicited their effects by specifically inhibiting c-Myc/Max complex formation [150]. One molecule, 10058-F4, has been extensively studied and found to induce cell cycle arrest, apoptosis, and differentiation in some cells in addition to its disruption of Myc/Max [151, 152]. However, the relatively low potencies of the identified Myc/Max compounds called for attempts to improve their efficacy, a challenge that was taken on by Prochownik et al. They have chemically modified 10058-F4 to generate analogues with improved efficacy that are better suitable for in vivo treatment [153]. By this approach, they showed that 10058F4 and its analogues bind directly to monomeric Myc, which may be important in design of even more potent compounds in the future. These analogues may have a higher in vivo stability than the original 10058-F4 structure that was recently reported to have a very short half-life, limiting its applications as an anti-tumour agent [154].

$\mathrm{Xu}$ et al. based their screen on the design and synthesis of a so-called credit-card library consisting of 285 substances. Several compounds with the ability to disrupt c-Myc/Max interaction were identified, some of which inhibited Mycinduced transformation in vitro [155]. Yet another approach was employed by $\mathrm{Lu}$ et al. who based their screen on a luciferase reporter gene under the control of the promoter of Ornithine decarboxylase (Odc), a MYCN target gene. By screening 2,800 molecules, five candidate molecules with inhibitory activities specific for MYCN overexpressing cells were identified [156]. Further evaluation of these compounds may reveal their specific molecular targets and determine their suitability as lead molecules.

In line with the above mentioned studies, we applied a cellular screening strategy in search for compounds that specifically inhibited proliferation in cells overexpressing c-Myc without affecting those with low c-Myc levels. With this approach, several candidate substances were identified that induced apoptosis and inhibited transformation in a c-Myc-dependent manner. None of the substances interfered with c-Myc/Max dimerization but targeted the Myc pathway at other levels [157]. In addition, these compounds inhibited cell proliferation in MYCN overexpressing neuroblastoma cells much more potently than in cells with low MYCN levels [158]. Recently, we have initiated a screen to identify small molecules that specifically affect $M Y C N$-amplified neuroblastoma cells in an anti-proliferative or a pro-apoptotic manner (M. Vita and M. Henriksson, unpublished data).

Indirect targeting of MYCN can be achieved by inducing differentiation of neuroblastoma cells, using for instance retinoic acid (RA). This method is already in clinical use, both for treatment of neuroblastoma and certain lymphomas. It has been shown that differentiation induction rapidly decreases expression and DNA binding activity of MYCN in MYCN amplified, but only modestly so in non-amplified neuroblastoma cells [159]. In a similar manner, RA in combination with IFN- $\gamma$ treatment downregulates $\mathrm{MYCN}$ protein expression in vitro, and shows promise for future clinical use [160]. A recent study showed a reduced MYCN expression when MYCN amplified neuroblastoma cells were treated with RA in combination with vasoactive intestinal peptide (VIP), a neuropeptide known to control proliferation or differentiation of numerous cancer cells [161]. The possibility of using RA treatment is being explored also in treatment of medulloblastoma, and in vitro data indicate that cell cycle arrest is induced via inhibition of c-Myc [162].

Despite the promising outlook in targeting Myc as a therapeutic approach in medulloblastoma, there are very 
few studies exploring this possibility. Both $c-M y c$ and $M Y C N$ have been found amplified in medulloblastoma and shown to mediate the effects of pathways such as Hedgehog, Wnt, c-Met, and IGF-R (reviewed in [11]). It would therefore be highly desirable to identify Myc inhibitors that can be brought to clinical trials for medulloblastoma treatment and to be further developed into clinically useful drugs.

\section{Conclusions}

Taken together, the several lines of evidence described above suggests that embryonal tumours of the nervous system have adopted many of the mechanisms to restrain apoptosis from their respective progenitor cells. This together with the fact that current therapeutic intensity for unfavourable medulloblastoma and high-risk neuroblastoma has advanced to near tolerance with limited gains in survival, implies that further improvements in outcome will require novel treatment approaches that potentiate the available therapy. One of the major challenges for such therapies will be to directly target the cancer cells without affecting the normal progenitor cells. This is especially important since these tumours in most cases develop in very young children. Therefore, treatment approaches that also affect the normal progenitor cells will have detrimental effects on the patient and should be avoided as far as possible. Here we have outlined the major pathways involved in disease progression and discussed a few of the ongoing studies in search for potential new therapies, some of which are already showing promising results in clinical trials.

Acknowledgments We apologize to our colleagues whose work we were unable to cite due to space limitations and to the specific focus of this review. We thank Dr B. Sveinbjörnson for critical reading of the manuscript. Research from the authors' laboratories are supported by grants from the Swedish Cancer Society, the Swedish Research Council, the Swedish Childhood Cancer Society, King Gustaf V Jubilee Foundation, Karolinska Institutet, and KICancer.

Open Access This article is distributed under the terms of the Creative Commons Attribution Noncommercial License which permits any noncommercial use, distribution, and reproduction in any medium, provided the original author(s) and source are credited.

\section{References}

1. Pritchard-Jones K, Kaatsch P, Steliarova-Foucher E, Stiller CA, Coebergh JW (2006) Cancer in children and adolescents in Europe: developments over 20 years and future challenges. Eur J Cancer 42:2183-2190. doi:10.1016/j.ejca.2006.06.006

2. Heron M (2007) Deaths: leading causes for 2004. National vital statistics reports. National Center for Health Statistics, Hyatsville
3. Gustafsson G, Heyman M, Vernby $\AA$ (eds) (2007) Childhood cancer incidence and survival in Sweden 1984-2005. Report 2007 from the Swedish childhood cancer registry. Karolinska Institutet, Stockholm, Sweden, p 92

4. Reamonn PE (2006) Childhood cancer: rising to the challenge. In: (UICC) IUAC (ed) World Cancer Campaign. International Union Against Cancer (UICC), Geneva, Switzerland, p 43

5. Gilbertson RJ (2004) Medulloblastoma: signalling a change in treatment. Lancet Oncol 5:209-218. doi:10.1016/S1470-2045 (04)01424-X

6. Brodeur GM (2003) Neuroblastoma: biological insights into a clinical enigma. Nat Rev Cancer 3:203-216. doi:10.1038/ nrc1014

7. Vassal G (2005) Has chemotherapy reached its limits in pediatric cancers? Eur J Cancer 41:564-575. doi:10.1016/j.ejca. 2004.08.030 (discussion 576-567)

8. Macy ME, Sawczyn KK, Garrington TP, Graham DK, Gore L (2008) Pediatric developmental therapies: interesting new drugs now in early-stage clinical trials. Curr Oncol Rep 10:477-490. doi:10.1007/s11912-008-0073-0

9. Herms J, Neidt I, Luscher B et al (2000) C-MYC expression in medulloblastoma and its prognostic value. Int J Cancer 89:395402. doi:10.1002/1097-0215(20000920)89:5<395::AID-IJC1> 3.0.CO;2-V

10. Eberhart CG, Kratz J, Wang Y et al (2004) Histopathological and molecular prognostic markers in medulloblastoma: c-myc, $\mathrm{N}$ myc, TrkC, and anaplasia. J Neuropathol Exp Neurol 63:441-449

11. Guessous F, Li Y, Abounader R (2008) Signaling pathways in medulloblastoma. J Cell Physiol 217:577-583. doi:10.1002/ jcp. 21542

12. Grimmer MR, Weiss WA (2006) Childhood tumors of the nervous system as disorders of normal development. Curr Opin Pediatr 18:634-638. doi:10.1097/MOP.0b013e32801080fe

13. Scotting PJ, Walker DA, Perilongo G (2005) Childhood solid tumours: a developmental disorder. Nat Rev Cancer 5:481-488. doi:10.1038/nrc1633

14. Klaus A, Birchmeier W (2008) Wnt signalling and its impact on development and cancer. Nat Rev Cancer 8:387-398. doi: $10.1038 / \mathrm{nrc} 2389$

15. Marino S (2005) Medulloblastoma: developmental mechanisms out of control. Trends Mol Med 11:17-22. doi:10.1016/ j.molmed.2004.11.008

16. Yang ZJ, Ellis T, Markant SL et al (2008) Medulloblastoma can be initiated by deletion of patched in lineage-restricted progenitors or stem cells. Cancer Cell 14:135-145. doi:10.1016/ j.ccr.2008.07.003

17. Schuller U, Heine VM, Mao J et al (2008) Acquisition of granule neuron precursor identity is a critical determinant of progenitor cell competence to form Shh-induced medulloblastoma. Cancer Cell 14:123-134. doi:10.1016/j.ccr.2008.07.005

18. Ho KS, Scott MP (2002) Sonic hedgehog in the nervous system: functions, modifications and mechanisms. Curr Opin Neurobiol 12:57-63. doi:10.1016/S0959-4388(02)00290-8

19. de Pablo F, de la Rosa EJ (1995) The developing CNS: a scenario for the action of proinsulin, insulin and insulin-like growth factors. Trends Neurosci 18:143-150. doi:10.1016/0166-2236 (95) $93892-2$

20. Hambardzumyan D, Becher OJ, Holland EC (2008) Cancer stem cells and survival pathways. Cell Cycle 7:1371-1378

21. Fodde R, Brabletz T (2007) Wnt/beta-catenin signaling in cancer stemness and malignant behavior. Curr Opin Cell Biol 19:150-158. doi:10.1016/j.ceb.2007.02.007

22. Johnsen JI, Segerstrom L, Orrego A et al (2008) Inhibitors of mammalian target of rapamycin downregulate MYCN protein expression and inhibit neuroblastoma growth in vitro and in vivo. Oncogene 27:2910-2922. doi:10.1038/sj.onc.1210938 
23. Opel D, Poremba C, Simon T, Debatin KM, Fulda S (2007) Activation of Akt predicts poor outcome in neuroblastoma. Cancer Res 67:735-745. doi:10.1158/0008-5472.CAN-06-2201

24. Liu X, Mazanek P, Dam V et al (2008) Deregulated Wnt/betacatenin program in high-risk neuroblastomas without MYCN amplification. Oncogene 27:1478-1488. doi:10.1038/sj.onc. 1210769

25. Chesler L, Schlieve C, Goldenberg DD et al (2006) Inhibition of phosphatidylinositol 3-kinase destabilizes Mycn protein and blocks malignant progression in neuroblastoma. Cancer Res 66:8139-8146. doi:10.1158/0008-5472.CAN-05-2769

26. Blaschke AJ, Weiner JA, Chun J (1998) Programmed cell death is a universal feature of embryonic and postnatal neuroproliferative regions throughout the central nervous system. J Comp Neurol 396:39-50. doi:10.1002/(SICI)1096-9861(19980622) 396:1<39::AID-CNE4>3.0.CO;2-J

27. De Zio D, Giunta L, Corvaro M, Ferraro E, Cecconi F (2005) Expanding roles of programmed cell death in mammalian neurodevelopment. Semin Cell Dev Biol 16:281-294. doi: 10.1016/j.semcdb.2004.12.003

28. Thornberry NA, Lazebnik Y (1998) Caspases: enemies within. Science 281:1312-1316. doi:10.1126/science.281.5381.1312

29. Degterev A, Yuan J (2008) Expansion and evolution of cell death programmes. Nat Rev Mol Cell Biol 9:378-390. doi: $10.1038 / \mathrm{nrm} 2393$

30. Schimmer AD (2004) Inhibitor of apoptosis proteins: translating basic knowledge into clinical practice. Cancer Res 64:71837190. doi:10.1158/0008-5472.CAN-04-1918

31. Mita AC, Mita MM, Nawrocki ST, Giles FJ (2008) Survivin: key regulator of mitosis and apoptosis and novel target for cancer therapeutics. Clin Cancer Res 14:5000-5005. doi: 10.1158/1078-0432.CCR-08-0746

32. Fulda S (2007) Inhibitor of apoptosis proteins as targets for anticancer therapy. Expert Rev Anticancer Ther 7:1255-1264. doi:10.1586/14737140.7.9.1255

33. Iannolo G, Conticello C, Memeo L, De Maria R (2008) Apoptosis in normal and cancer stem cells. Crit Rev Oncol Hematol 66:42-51. doi:10.1016/j.critrevonc.2007.09.004

34. Antonsson B, Martinou JC (2000) The Bcl-2 protein family. Exp Cell Res 256:50-57. doi:10.1006/excr.2000.4839

35. Ricci-Vitiani L, Pedini F, Mollinari C et al (2004) Absence of caspase 8 and high expression of PED protect primitive neural cells from cell death. J Exp Med 200:1257-1266. doi:10.1084/ jem.20040921

36. Pingoud-Meier C, Lang D, Janss AJ et al (2003) Loss of caspase- 8 protein expression correlates with unfavorable survival outcome in childhood medulloblastoma. Clin Cancer Res 9:6401-6409

37. Fulda S, Poremba C, Berwanger B et al (2006) Loss of caspase- 8 expression does not correlate with MYCN amplification, aggressive disease, or prognosis in neuroblastoma. Cancer Res 66:10016-10023. doi:10.1158/0008-5472.CAN-05-4079

38. Teitz T, Wei T, Valentine MB et al (2000) Caspase 8 is deleted or silenced preferentially in childhood neuroblastomas with amplification of MYCN. Nat Med 6:529-535. doi:10.1038/75007

39. Yang Q, Kiernan CM, Tian Y et al (2007) Methylation of CASP8, DCR2, and HIN-1 in neuroblastoma is associated with poor outcome. Clin Cancer Res 13:3191-3197. doi:10.1158/ 1078-0432.CCR-06-2846

40. Gonzalez-Gomez P, Bello MJ, Lomas J et al (2003) Aberrant methylation of multiple genes in neuroblastic tumours. Relationship with MYCN amplification and allelic status at 1p. Eur J Cancer 39:1478-1485. doi:10.1016/S0959-8049(03)00312-5

41. Grotzer MA, Eggert A, Zuzak TJ et al (2000) Resistance to TRAIL-induced apoptosis in primitive neuroectodermal brain tumor cells correlates with a loss of caspase-8 expression. Oncogene 19:4604-4610. doi:10.1038/sj.onc.1203816

42. Poulaki V, Mitsiades N, Romero ME, Tsokos M (2001) Fasmediated apoptosis in neuroblastoma requires mitochondrial activation and is inhibited by FLICE inhibitor protein and Bcl-2. Cancer Res 61:4864-4872

43. Krueger A, Baumann S, Krammer PH, Kirchhoff S (2001) FLICE-inhibitory proteins: regulators of death receptor-mediated apoptosis. Mol Cell Biol 21:8247-8254. doi:10.1128/ MCB.21.24.8247-8254.2001

44. Goldsmith KC, Hogarty MD (2005) Targeting programmed cell death pathways with experimental therapeutics: opportunities in high-risk neuroblastoma. Cancer Lett 228:133-141. doi: 10.1016/j.canlet.2005.01.048

45. Fulda S, Debatin KM (2003) Apoptosis pathways in neuroblastoma therapy. Cancer Lett 197:131-135. doi:10.1016/ S0304-3835(03)00091-0

46. Arbour N, Vanderluit JL, Le Grand JN et al (2008) Mcl-1 is a key regulator of apoptosis during CNS development and after DNA damage. J Neurosci 28:6068-6078. doi:10.1523/ JNEUROSCI.4940-07.2008

47. Michels J, Johnson PW, Packham G (2005) Mcl-1. Int J Biochem Cell Biol 37:267-271. doi:10.1016/j.biocel.2004.04.007

48. Craig RW (2002) MCL1 provides a window on the role of the BCL2 family in cell proliferation, differentiation and tumorigenesis. Leukemia 16:444-454. doi:10.1038/sj.leu.2402416

49. Opferman JT, Letai A, Beard C, Sorcinelli MD, Ong CC, Korsmeyer SJ (2003) Development and maintenance of B and T lymphocytes requires antiapoptotic MCL-1. Nature 426:671676. doi: $10.1038 /$ nature 02067

50. Lossi L, Zagzag D, Greco MA, Merighi A (1998) Apoptosis of undifferentiated progenitors and granule cell precursors in the postnatal human cerebellar cortex correlates with expression of BCL-2, ICE, and CPP32 proteins. J Comp Neurol 399:359-372. doi:10.1002/(SICI)1096-9861(19980928)399:3<359::AID-CNE5> 3.0.CO;2-\#

51. Tanabe H, Eguchi Y, Kamada S, Martinou JC, Tsujimoto Y (1997) Susceptibility of cerebellar granule neurons derived from Bcl-2-deficient and transgenic mice to cell death. Eur J NeuroSci 9:848-856. doi:10.1111/j.1460-9568.1997.tb01434.x

52. Bar EE, Chaudhry A, Farah MH, Eberhart CG (2007) Hedgehog signaling promotes medulloblastoma survival via Bc/II. Am J Pathol 170:347-355. doi:10.2353/ajpath.2007.060066

53. McCall TD, Pedone CA, Fults DW (2007) Apoptosis suppression by somatic cell transfer of Bcl-2 promotes Sonic hedgehogdependent medulloblastoma formation in mice. Cancer Res 67:5179-5185. doi:10.1158/0008-5472.CAN-06-4177

54. Abel F, Sjoberg RM, Nilsson S, Kogner P, Martinsson T (2005) Imbalance of the mitochondrial pro- and anti-apoptotic mediators in neuroblastoma tumours with unfavourable biology. Eur $\mathbf{J}$ Cancer 41:635-646. doi:10.1016/j.ejca.2004.12.021

55. Castle VP, Heidelberger KP, Bromberg J, Ou X, Dole M, Nunez G (1993) Expression of the apoptosis-suppressing protein bcl-2, in neuroblastoma is associated with unfavorable histology and N-myc amplification. Am J Pathol 143:1543-1550

56. Ushmorov A, Hogarty MD, Liu X, Knauss H, Debatin KM, Beltinger C (2008) N-myc augments death and attenuates protective effects of Bcl-2 in trophically stressed neuroblastoma cells. Oncogene 27:3424-3434. doi:10.1038/sj.onc.1211017

57. Lo KC, Ma C, Bundy BN, Pomeroy SL, Eberhart CG, Cowell JK (2007) Gain of 1q is a potential univariate negative prognostic marker for survival in medulloblastoma. Clin Cancer Res 13:7022-7028. doi:10.1158/1078-0432.CCR-07-1420

58. Bown N, Cotterill S, Lastowska M et al (1999) Gain of chromosome arm $17 \mathrm{q}$ and adverse outcome in patients with 
neuroblastoma. N Engl J Med 340:1954-1961. doi:10.1056/ NEJM199906243402504

59. Kool M, Koster J, Bunt J et al (2008) Integrated genomics identifies five medulloblastoma subtypes with distinct genetic profiles, pathway signatures and clinicopathological features. PLoS ONE 3:e3088. doi:10.1371/journal.pone.0003088

60. Islam A, Kageyama H, Takada $\mathrm{N}$ et al (2000) High expression of survivin, mapped to $17 \mathrm{q} 25$, is significantly associated with poor prognostic factors and promotes cell survival in human neuroblastoma. Oncogene 19:617-623. doi:10.1038/sj.onc. 1203358

61. Haberler C, Slave I, Czech T et al (2006) Histopathological prognostic factors in medulloblastoma: high expression of survivin is related to unfavourable outcome. Eur J Cancer 42:29963003. doi:10.1016/j.ejca.2006.05.038

62. Adida C, Berrebi D, Peuchmaur M, Reyes-Mugica M, Altieri DC (1998) Anti-apoptosis gene, survivin, and prognosis of neuroblastoma. Lancet 351:882-883. doi:10.1016/S01406736(05)70294-4

63. Kobayashi K, Hatano M, Otaki M, Ogasawara T, Tokuhisa T (1999) Expression of a murine homologue of the inhibitor of apoptosis protein is related to cell proliferation. Proc Natl Acad Sci USA 96:1457-1462. doi:10.1073/pnas.96.4.1457

64. Li F, Altieri DC (1999) The cancer antiapoptosis mouse survivin gene: characterization of locus and transcriptional requirements of basal and cell cycle-dependent expression. Cancer Res 59:3143-3151

65. Hattori M, Sakamoto H, Satoh K, Yamamoto T (2001) DNA demethylase is expressed in ovarian cancers and the expression correlates with demethylation of $\mathrm{CpG}$ sites in the promoter region of c-erbB-2 and survivin genes. Cancer Lett 169:155164. doi:10.1016/S0304-3835(01)00499-2

66. Vaira V, Lee CW, Goel HL, Bosari S, Languino LR, Altieri DC (2007) Regulation of survivin expression by IGF-1/mTOR signaling. Oncogene 26:2678-2684. doi:10.1038/sj.onc.1210094

67. Saylors RLIII, Sidransky D, Friedman HS et al (1991) Infrequent p53 gene mutations in medulloblastomas. Cancer Res 51:4721-4723

68. Adesina AM, Nalbantoglu J, Cavenee WK (1994) p53 gene mutation and $\mathrm{mdm} 2$ gene amplification are uncommon in medulloblastoma. Cancer Res 54:5649-5651

69. Chesler L, Goldenberg DD, Collins R et al (2008) Chemotherapy-induced apoptosis in a transgenic model of neuroblastoma proceeds through p53 induction. Neoplasia 10:1268-1274

70. Wetmore C, Eberhart DE, Curran T (2001) Loss of p53 but not ARF accelerates medulloblastoma in mice heterozygous for patched. Cancer Res 61:513-516

71. Weiss WA, Aldape K, Mohapatra G, Feuerstein BG, Bishop JM (1997) Targeted expression of MYCN causes neuroblastoma in transgenic mice. EMBO J 16:2985-2995. doi:10.1093/emboj/ 16.11.2985

72. Burnett ME, White EC, Sih S, von Haken MS, Cogen PH (1997) Chromosome arm $17 \mathrm{p}$ deletion analysis reveals molecular genetic heterogeneity in supratentorial and infratentorial primitive neuroectodermal tumors of the central nervous system. Cancer Genet Cytogenet 97:25-31. doi:10.1016/S0165-4608 (96)00319-6

73. Collins VP (2004) Brain tumours: classification and genes. J Neurol Neurosurg Psychiatry 75(Suppl 2):ii2-ii11. doi: 10.1136/jnnp.2004.040337

74. Frank AJ, Hernan R, Hollander A et al (2004) The TP53-ARF tumor suppressor pathway is frequently disrupted in large/cell anaplastic medulloblastoma. Brain Res Mol Brain Res 121:137140. doi:10.1016/j.molbrainres.2003.11.016

75. Tong CY, Hui AB, Yin XL et al (2004) Detection of oncogene amplifications in medulloblastomas by comparative genomic hybridization and array-based comparative genomic hybridization. J Neurosurg 100:187-193

76. Castellino RC, De Bortoli M, Lu X et al (2008) Medulloblastomas overexpress the p53-inactivating oncogene WIP1/ PPM1D. J Neurooncol 86:245-256. doi:10.1007/s11060007-9470-8

77. Keshelava N, Zuo JJ, Chen P et al (2001) Loss of p53 function confers high-level multidrug resistance in neuroblastoma cell lines. Cancer Res 61:6185-6193

78. Tweddle DA, Malcolm AJ, Bown N, Pearson AD, Lunec J (2001) Evidence for the development of p53 mutations after cytotoxic therapy in a neuroblastoma cell line. Cancer Res 61:813

79. Corvi R, Savelyeva L, Breit S et al (1995) Non-syntenic amplification of MDM2 and MYCN in human neuroblastoma. Oncogene 10:1081-1086

80. Valsesia-Wittmann S, Magdeleine M, Dupasquier S et al (2004) Oncogenic cooperation between $\mathrm{H}$-Twist and N-Myc overrides failsafe programs in cancer cells. Cancer Cell 6:625-630. doi: 10.1016/j.ccr.2004.09.033

81. Saito-Ohara F, Imoto I, Inoue $\mathbf{J}$ et al (2003) PPM1D is a potential target for $17 \mathrm{q}$ gain in neuroblastoma. Cancer Res 63:1876-1883

82. Thompson PM, Maris JM, Hogarty MD et al (2001) Homozygous deletion of CDKN2A (p16INK4a/p14ARF) but not within $1 \mathrm{p} 36$ or at other tumor suppressor loci in neuroblastoma. Cancer Res 61:679-686

83. Caren H, Erichsen J, Olsson L et al (2008) High-resolution array copy number analyses for detection of deletion, gain, amplification and copy-neutral LOH in primary neuroblastoma tumors: four cases of homozygous deletions of the CDKN2A gene. BMC Genomics 9:353. doi:10.1186/1471-2164-9-353

84. Casciano I, Mazzocco K, Boni L et al (2002) Expression of DeltaNp73 is a molecular marker for adverse outcome in neuroblastoma patients. Cell Death Differ 9:246-251. doi: 10.1038/sj.cdd. 4400993

85. Zitterbart K, Zavrelova I, Kadlecova J et al (2007) p73 expression in medulloblastoma: TAp73/DeltaNp73 transcript detection and possible association of p73alpha/DeltaNp73 immunoreactivity with survival. Acta Neuropathol 114:641650. doi:10.1007/s00401-007-0298-2

86. Morris SW, Kirstein MN, Valentine MB et al (1994) Fusion of a kinase gene, ALK, to a nucleolar protein gene, NPM, in nonHodgkin's lymphoma. Science 263:1281-1284. doi: $10.1126 /$ science. 8122112

87. Chiarle R, Voena C, Ambrogio C, Piva R, Inghirami G (2008) The anaplastic lymphoma kinase in the pathogenesis of cancer. Nat Rev Cancer 8:11-23. doi:10.1038/nrc2291

88. Pulford K, Lamant L, Espinos E et al (2004) The emerging normal and disease-related roles of anaplastic lymphoma kinase. Cell Mol Life Sci 61:2939-2953. doi:10.1007/s00018-0044275-9

89. Lamant L, Pulford K, Bischof D et al (2000) Expression of the ALK tyrosine kinase gene in neuroblastoma. Am J Pathol 156:1711-1721

90. McDermott U, Iafrate AJ, Gray NS et al (2008) Genomic alterations of anaplastic lymphoma kinase may sensitize tumors to anaplastic lymphoma kinase inhibitors. Cancer Res 68:33893395. doi:10.1158/0008-5472.CAN-07-6186

91. Mosse YP, Laudenslager M, Longo L et al (2008) Identification of ALK as a major familial neuroblastoma predisposition gene. Nature 455:930-935. doi:10.1038/nature07261

92. Caren H, Abel F, Kogner P, Martinsson T (2008) High incidence of DNA mutations and gene amplifications of the ALK gene in advanced sporadic neuroblastoma tumours. Biochem J 416:153159. doi:10.1042/BJ20081834 
93. Janoueix-Lerosey I, Lequin D, Brugieres L et al (2008) Somatic and germline activating mutations of the ALK kinase receptor in neuroblastoma. Nature 455:967-970. doi:10.1038/nature07398

94. Chen Y, Takita J, Choi YL et al (2008) Oncogenic mutations of ALK kinase in neuroblastoma. Nature 455:971-974. doi: 10.1038/nature07399

95. George RE, Sanda T, Hanna M et al (2008) Activating mutations in ALK provide a therapeutic target in neuroblastoma. Nature 455:975-978. doi:10.1038/nature07397

96. Li R, Morris SW (2008) Development of anaplastic lymphoma kinase (ALK) small-molecule inhibitors for cancer therapy. Med Res Rev 28:372-412. doi:10.1002/med.20109

97. Henderson CE, Yamamoto Y, Livet J, Arce V, Garces A, deLapeyriere O (1998) Role of neurotrophic factors in motoneuron development. J Physiol (Paris) 92:279-281. doi: 10.1016/S0928-4257(98)80033-8

98. Miller FD, Kaplan DR (2001) Neurotrophin signalling pathways regulating neuronal apoptosis. Cell Mol Life Sci 58:1045-1053. doi:10.1007/PL00000919

99. Smeyne RJ, Klein R, Schnapp A et al (1994) Severe sensory and sympathetic neuropathies in mice carrying a disrupted Trk/NGF receptor gene. Nature 368:246-249. doi:10.1038/368246a0

100. Nakagawara A, Azar CG, Scavarda NJ, Brodeur GM (1994) Expression and function of TRK-B and BDNF in human neuroblastomas. Mol Cell Biol 14:759-767

101. Li Z, Thiele CJ (2007) Targeting Akt to increase the sensitivity of neuroblastoma to chemotherapy: lessons learned from the brain-derived neurotrophic factor/TrkB signal transduction pathway. Expert Opin Ther Targets 11:1611-1621. doi:10.1517/ 14728222.11.12.1611

102. Nakagawara A, Arima-Nakagawara M, Scavarda NJ, Azar CG, Cantor AB, Brodeur GM (1993) Association between high levels of expression of the TRK gene and favorable outcome in human neuroblastoma. N Engl J Med 328:847-854. doi: 10.1056/NEJM199303253281205

103. Kogner P, Barbany G, Dominici C, Castello MA, Raschella G, Persson H (1993) Coexpression of messenger RNA for TRK protooncogene and low affinity nerve growth factor receptor in neuroblastoma with favorable prognosis. Cancer Res 53:2044-2050

104. Nakagawara A, Kogner P (2000) Expression and function of Trk and its related genes in human neuroblastoma. In: Brodeur GM, Sawada T, Tsuchida Y, Voûte PA (eds) Neuroblastoma. Elsevier, Amsterdam

105. Grotzer MA, Janss AJ, Fung K et al (2000) TrkC expression predicts good clinical outcome in primitive neuroectodermal brain tumors. J Clin Oncol 18:1027-1035

106. Ryden M, Sehgal R, Dominici C, Schilling FH, Ibanez CF, Kogner P (1996) Expression of mRNA for the neurotrophin receptor trkC in neuroblastomas with favourable tumour stage and good prognosis. Br J Cancer 74:773-779

107. Yamashiro DJ, Nakagawara A, Ikegaki N, Liu XG, Brodeur GM (1996) Expression of TrkC in favorable human neuroblastomas. Oncogene 12:37-41

108. Patapoutian A, Reichardt LF (2001) Trk receptors: mediators of neurotrophin action. Curr Opin Neurobiol 11:272-280. doi: 10.1016/S0959-4388(00)00208-7

109. Duronio V (2008) The life of a cell: apoptosis regulation by the PI3K/PKB pathway. Biochem J 415:333-344. doi:10.1042/ BJ20081056

110. Hartmann W, Digon-Sontgerath B, Koch A et al (2006) Phosphatidylinositol $3^{\prime}$-kinase/AKT signaling is activated in medulloblastoma cell proliferation and is associated with reduced expression of PTEN. Clin Cancer Res 12:3019-3027. doi:10.1158/1078-0432.CCR-05-2187
111. Hambardzumyan D, Becher OJ, Rosenblum MK, Pandolfi PP, Manova-Todorova K, Holland EC (2008) PI3K pathway regulates survival of cancer stem cells residing in the perivascular niche following radiation in medulloblastoma in vivo. Genes Dev 22:436-448. doi:10.1101/gad.1627008

112. Browd SR, Kenney AM, Gottfried ON et al (2006) N-myc can substitute for insulin-like growth factor signaling in a mouse model of sonic hedgehog-induced medulloblastoma. Cancer Res 66:2666-2672. doi:10.1158/0008-5472.CAN-05-2198

113. Barisone GA, Yun JS, Diaz E (2008) From cerebellar proliferation to tumorigenesis: new insights into the role of Mad3. Cell Cycle 7:423-427

114. Fox EJ, Wright SC (2001) S-phase-specific expression of the $\mathrm{Mad} 3$ gene in proliferating and differentiating cells. Biochem $\mathrm{J}$ 359:361-367. doi:10.1042/0264-6021:3590361

115. Hurlin PJ, Huang J (2006) The MAX-interacting transcription factor network. Semin Cancer Biol 16:265-274. doi:10.1016/ j.semcancer.2006.07.009

116. Li Y, Guessous F, Johnson EB et al (2008) Functional and molecular interactions between the HGF/c-Met pathway and c-Myc in large-cell medulloblastoma. Lab Invest 88:98-111. doi:10.1038/labinvest. 3700702

117. Stearns D, Chaudhry A, Abel TW, Burger PC, Dang CV, Eberhart CG (2006) c-myc overexpression causes anaplasia in medulloblastoma. Cancer Res 66:673-681. doi:10.1158/00085472.CAN-05-1580

118. Meyer N, Kim SS, Penn LZ (2006) The Oscar-worthy role of Myc in apoptosis. Semin Cancer Biol 16:275-287. doi:10.1016/ j.semcancer.2006.07.011

119. Grandori C, Cowley SM, James LP, Eisenman RN (2000) The Myc/ Max/Mad network and the transcriptional control of cell behavior. Annu Rev Cell Dev Biol 16:653-699. doi:10.1146/annurev. cellbio.16.1.653

120. Vita M, Henriksson M (2006) The Myc oncoprotein as a therapeutic target for human cancer. Semin Cancer Biol 16:318 330. doi:10.1016/j.semcancer.2006.07.015

121. Albihn A, Mo H, Yang Y, Henriksson M (2007) Camptothecininduced apoptosis is enhanced by Myc and involves PKCdelta signaling. Int $\mathrm{J}$ Cancer 121:1821-1829. doi:10.1002/ijc. 22866

122. Fulda S, Lutz W, Schwab M, Debatin KM (1999) MycN sensitizes neuroblastoma cells for drug-induced apoptosis. Oncogene 18:1479-1486. doi:10.1038/sj.onc.1202435

123. Paffhausen T, Schwab M, Westermann F (2007) Targeted MYCN expression affects cytotoxic potential of chemotherapeutic drugs in neuroblastoma cells. Cancer Lett 250:17-24. doi: 10.1016/j.canlet.2006.09.010

124. Albihn A, Loven J, Ohlsson J, Osorio LM, Henriksson M (2006) c-Myc-dependent etoposide-induced apoptosis involves activation of Bax and caspases, and PKCdelta signaling. J Cell Biochem 98:1597-1614. doi:10.1002/jcb.20816

125. Dole M, Nunez G, Merchant AK et al (1994) Bcl-2 inhibits chemotherapy-induced apoptosis in neuroblastoma. Cancer Res 54:3253-3259

126. Ashkenazi A (2002) Targeting death and decoy receptors of the tumour-necrosis factor superfamily. Nat Rev Cancer 2:420-430. doi: $10.1038 / \mathrm{nrc} 821$

127. Johnstone RW, Frew AJ, Smyth MJ (2008) The TRAIL apoptotic pathway in cancer onset, progression and therapy. Nat Rev Cancer 8:782-798. doi:10.1038/nrc2465

128. Johnsen JI, Pettersen I, Ponthan F, Sveinbjornsson B, Flaegstad T, Kogner P (2004) Synergistic induction of apoptosis in neuroblastoma cells using a combination of cytostatic drugs with interferon-gamma and TRAIL. Int J Oncol 25:1849-1857 
129. Yang X, Merchant MS, Romero ME et al (2003) Induction of caspase 8 by interferon gamma renders some neuroblastoma (NB) cells sensitive to tumor necrosis factor-related apoptosisinducing ligand (TRAIL) but reveals that a lack of membrane TR1/TR2 also contributes to TRAIL resistance in NB. Cancer Res 63:1122-1129

130. Fulda S, Debatin KM (2002) IFNgamma sensitizes for apoptosis by upregulating caspase- 8 expression through the Stat 1 pathway. Oncogene 21:2295-2308. doi:10.1038/sj.onc.1205255

131. Kim SH, Ricci MS, El-Deiry WS (2008) Mcl-1: a gateway to TRAIL sensitization. Cancer Res 68:2062-2064. doi:10.1158/ 0008-5472.CAN-07-6278

132. van Delft MF, Huang DC (2006) How the Bcl-2 family of proteins interact to regulate apoptosis. Cell Res 16:203-213. doi:10.1038/sj.cr.7310028

133. Stein CA, Benimetskaya L, Mani S (2005) Antisense strategies for oncogene inactivation. Semin Oncol 32:563-572. doi: 10.1053/j.seminoncol.2005.09.003

134. Goldsmith KC, Liu X, Dam V et al (2006) BH3 peptidomimetics potently activate apoptosis and demonstrate single agent efficacy in neuroblastoma. Oncogene 25:4525-4533. doi: 10.1038/sj.onc. 1209489

135. Azmi AS, Mohammad RM (2009) Non-peptidic small molecule inhibitors against Bcl-2 for cancer therapy. J Cell Physiol 218:13-21. doi:10.1002/jcp.21567

136. Zeitlin BD, Zeitlin IJ, Nor JE (2008) Expanding circle of inhibition: small-molecule inhibitors of Bcl-2 as anticancer cell and antiangiogenic agents. J Clin Oncol 26:4180-4188. doi:10.1200/ JCO.2007.15.7693

137. Coughlin CM, Fleming MD, Carroll RG et al (2006) Immunosurveillance and survivin-specific T-cell immunity in children with high-risk neuroblastoma. J Clin Oncol 24:5725-5734. doi: 10.1200/JCO.2005.05.3314

138. Deubzer HE, Ehemann V, Westermann F et al (2008) Histone deacetylase inhibitor Helminthosporium carbonum (HC)-toxin suppresses the malignant phenotype of neuroblastoma cells. Int $\mathbf{J}$ Cancer 122:1891-1900. doi:10.1002/ijc.23295

139. Baryawno N, Sveinbjornsson B, Eksborg S et al (2008) Tumorgrowth-promoting cyclooxygenase-2 prostaglandin E2 pathway provides medulloblastoma therapeutic targets. Neuro-oncol 10:661-674. doi:10.1215/15228517-2008-035

140. Johnsen JI, Lindskog M, Ponthan F et al (2004) Cyclooxygenase-2 is expressed in neuroblastoma, and nonsteroidal antiinflammatory drugs induce apoptosis and inhibit tumor growth in vivo. Cancer Res 64:7210-7215. doi:10.1158/0008-5472. CAN-04-1795

141. Johnsen JI, Lindskog M, Ponthan F et al (2005) NSAIDs in neuroblastoma therapy. Cancer Lett 228:195-201. doi:10.1016/ j.canlet.2005.01.058

142. Ponthan F, Wickstrom M, Gleissman H et al (2007) Celecoxib prevents neuroblastoma tumor development and potentiates the effect of chemotherapeutic drugs in vitro and in vivo. Clin Cancer Res 13:1036-1044. doi:10.1158/1078-0432.CCR-06-1908

143. Pyrko P, Soriano N, Kardosh A et al (2006) Downregulation of survivin expression and concomitant induction of apoptosis by celecoxib and its non-cyclooxygenase-2-inhibitory analog, dimethyl-celecoxib (DMC), in tumor cells in vitro and in vivo. Mol Cancer 5:19. doi:10.1186/1476-4598-5-19

144. Pession A, Tonelli R, Fronza R et al (2004) Targeted inhibition of NMYC by peptide nucleic acid in N-myc amplified human neuroblastoma cells: cell-cycle inhibition with induction of neuronal cell differentiation and apoptosis. Int J Oncol 24:265-272

145. Galderisi U, Di Bernardo G, Cipollaro M et al (1999) Differentiation and apoptosis of neuroblastoma cells: role of $\mathrm{N}-\mathrm{myc}$ gene product. J Cell Biochem 73:97-105. doi:10.1002/(SICI) 1097-4644(19990401)73:1<97::AID-JCB11>3.0.CO;2-M
146. Burkhart CA, Cheng AJ, Madafiglio J et al (2003) Effects of MYCN antisense oligonucleotide administration on tumorigenesis in a murine model of neuroblastoma. J Natl Cancer Inst 95:1394-1403

147. Sarkar AK, Nuchtern JG (2000) Lysis of MYCN-amplified neuroblastoma cells by MYCN peptide-specific cytotoxic T lymphocytes. Cancer Res 60:1908-1913

148. Soucek L, Whitfield J, Martins CP et al (2008) Modelling Myc inhibition as a cancer therapy. Nature 455:679-683. doi: 10.1038/nature07260

149. Berg T, Cohen SB, Desharnais J et al (2002) Small-molecule antagonists of Myc/Max dimerization inhibit Myc-induced transformation of chicken embryo fibroblasts. Proc Natl Acad Sci USA 99:3830-3835. doi:10.1073/pnas.062036999

150. Yin X, Giap C, Lazo JS, Prochownik EV (2003) Low molecular weight inhibitors of Myc-Max interaction and function. Oncogene 22:6151-6159. doi:10.1038/sj.onc. 1206641

151. Huang MJ, Cheng YC, Liu CR, Lin S, Liu HE (2006) A smallmolecule c-Myc inhibitor, 10058-F4, induces cell-cycle arrest, apoptosis, and myeloid differentiation of human acute myeloid leukemia. Exp Hematol 34:1480-1489. doi:10.1016/j.exphem. 2006.06.019

152. Lin CP, Liu JD, Chow JM, Liu CR, Liu HE (2007) Smallmolecule c-Myc inhibitor, 10058-F4, inhibits proliferation, downregulates human telomerase reverse transcriptase and enhances chemosensitivity in human hepatocellular carcinoma cells. Anticancer Drugs 18:161-170. doi:10.1097/CAD. 0b013e3280109424

153. Wang H, Hammoudeh DI, Follis AV et al (2007) Improved low molecular weight Myc-Max inhibitors. Mol Cancer Ther 6:2399-2408. doi:10.1158/1535-7163.MCT-07-0005

154. Guo J, Parise RA, Joseph E et al (2008) Efficacy, pharmacokinetics, tisssue distribution, and metabolism of the Myc-Max disruptor, 10058-F4 [Z,E]-5-[4-ethylbenzylidine]-2-thioxothiazolidin-4-one, in mice. Cancer Chemother Pharmacol 63(4):615-625. doi:10.1007/s00280-008-0774-y

155. Xu Y, Shi J, Yamamoto N, Moss JA, Vogt PK, Janda KD (2006) A credit-card library approach for disrupting protein-protein interactions. Bioorg Med Chem 14:2660-2673. doi:10.1016/j.bmc. 2005.11.052

156. Lu X, Pearson A, Lunec J (2003) The MYCN oncoprotein as a drug development target. Cancer Lett 197:125-130. doi: 10.1016/S0304-3835(03)00096-X

157. Mo H, Henriksson M (2006) Identification of small molecules that induce apoptosis in a Myc-dependent manner and inhibit Myc-driven transformation. Proc Natl Acad Sci USA 103:63446349. doi:10.1073/pnas.0601418103

158. Mo H, Vita M, Crespin M, Henriksson M (2006) Myc overexpression enhances apoptosis induced by small molecules. Cell Cycle 5:2191-2194

159. Smith AG, Popov N, Imreh M, Axelson H, Henriksson M (2004) Expression and DNA-binding activity of MYCN/Max and Mnt/ Max during induced differentiation of human neuroblastoma cells. J Cell Biochem 92:1282-1295. doi:10.1002/jcb.20121

160. Cetinkaya C, Hultquist A, Su Y et al (2007) Combined IFNgamma and retinoic acid treatment targets the N-Myc/Max/ Mad1 network resulting in repression of N-Myc target genes in MYCN-amplified neuroblastoma cells. Mol Cancer Ther 6:2634-2641. doi:10.1158/1535-7163.MCT-06-0492

161. Chevrier L, Meunier AC, Cochaud S, Muller JM, Chadeneau C (2008) Vasoactive intestinal peptide decreases MYCN expression and synergizes with retinoic acid in a human MYCNamplified neuroblastoma cell line. Int J Oncol 33:1081-1089

162. Chang Q, Chen Z, You J et al (2007) All-trans-retinoic acid induces cell growth arrest in a human medulloblastoma cell line. J Neurooncol 84:263-267. doi:10.1007/s11060-007-9380-9 